the New York Academy of Sciences, 1956, 67, 123-164.

LAZARUS, R. S., \& OPTON, E. M., JR. The study of psychological stress: $A$ summary of theoretical formulations and experimental findings. In C. D. Spielberger (Ed.), Anxiety and behavior. New York: Academic Press, 1966. Pp. 225-262.

ZIMBARDO, P. G., COHEN, A. R., WEISENBERG, M., DWORKIN, L., \& FIRESTONE, I. Control of pain motivation by cognitive dissonance. Science, 1966, 151, 217-219.

1. The research reported in this paper was made possible by Research Grant GS-1354 from the National Science Foundation and by a grant from Russell Sage Foundation. We are indebted to Mr. Andrew Gordon of our laboratory at the Rockefeller, who wrote the computer program for converting skin resistane data into autonomic lability scores. Thanks are also due to Judy Larkin who helped in the design and analysis of this research.

2. An analysis of variance of the ALS scores for the first film viewing period did not show a significant main effect due to treatments. Indeed, a plot of these data revealed that the curves were clustered together rather closely.

\title{
The cognitive factor in the extinction of a conditioned GSR
}

PHILIP S. HALL and CAROL R. PRIOR, Keuka College, Keuka Park, N.Y. 14478

This study investigated the effect of cognition on the extinction of a conditioned $G S R$. The difference between extinction rates indicated that the Ss who could form the cognition that the UCS would no longer be presented extinguished more rapidly than Ss who could not. The data were interpreted as support for the role of awareness in the extinction of a classically conditioned response.

Spielberger \& DeNike (1966) investigated the hypothesis that awareness is essential in verbal operant conditioning (VOC). Most of the subsequent evidence (David, 1967; Miller, 1967; and Mondy, 1968) supports the position that in VOC awareness precedes or occurs concurrently with response modification.

The effect of awareness in VOC suggests there may be a cognitive factor in the classically conditioned human responses. Spence (1966) postulated the existence of a cognitive factor to explain the more rapid extinction of the conditioned eye blink in humans than in rabbits. The influence of this cognitive factor was effectively diminished by verbal instructions which masked the fact that the experiment involved classical conditioning. When the Ss were informed that they were involved in a probability matching task, the extinction rate of the conditioned response was significantly slower.

This study investigated further the effect of cognition on the extinction of a classically conditioned response. It was hypothesized that Ss aided in forming the cognition that the UCS will be absent, extinguish more rapidly than Ss not aided. SUBJECTS

The Ss were 13 females enrolled in an introductory psychology class. APPARATUS

The UCS was a shock of $55 \mathrm{~V}$. The CS was a green $2 \times 2$ in. square mounted on a panel in a horizontal line with four squares of equal size but different color. A trial was defined by the illumination of a square for $4 \mathrm{sec}$ followed by a 4 -sec interval of no illumination. The illumination sequence was randomized. The S's GSR was measured by a Marrietta Model 12-13 recorder which graphed the per cent change in the S's skin resistance.

\section{PROCEDURE}

Each $S$ was seated before the panel in a small dimly lighted room. She was asked to observe the lights and instructed that she would occasionally receive a shock. The E conditioned the $\mathrm{S}$ from an adjoining room. When a CR was established the $E$ removed, without comment, the electrode for half of the Ss. The electrode was merely adjusted for the other Ss.

\section{RESULTS}

Three of the Ss were excluded because no CR was established. The scores for the remaining Ss were obtained by measuring, to the nearest millimeter, the difference between the GSR at the onset of the CS and the maximum GSR occurring within $10 \mathrm{sec}$. It can be seen in Fig. 1 that the Ss who had the electrode removed extinguished more

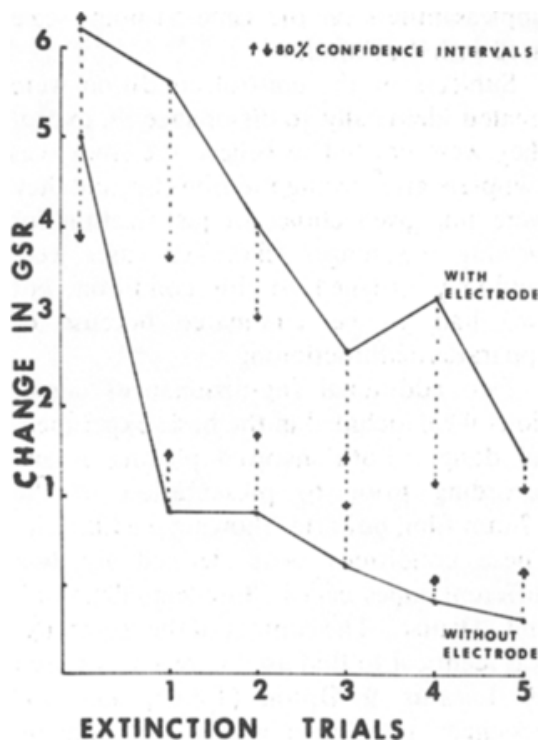

Figure 1.

rapidly than the Ss who did not. The $80 \%$ confidence interval plotted around each sample mean is evidence that these are significantly different rates of extinction.

DISCUSSION

One explanation for the different rates of extinction is: the Ss who had the electrode removed extinguished to a CS different from the one to which they had been conditioned. This explanation suggests that the rapid rate of extinction is attributable to the subtle but significant change in the CS. This interpretation of the data places a great deal of importance on a minimal change in the CS.

In view of the importance of awareness in VOC a more tenable explanation is: the Ss who had the electrode removed were aware that a shock would no longer be received. The cognition that there would no longer be a shock reduced the drive and suppressed the CR.

This data is interpreted to support the hypothesis that the S's awareness of the removal of the UCS results in immediate extinction of a classically conditioned response.

\section{REFERENCES}

DAVID, K. H. Effect of a speed set on awareness and verbal operant conditioning. Psychological Reports, 1967, 21, 549-552.

MILLER, A. W. Awareness, verbal conditioning, and meaning conditioning. Psychological Reports, 1967, 21,681-691.

MONDY, L. W. Degrees of awareness and intentions to comply in verbal conditioning. Psychological Reports, 1968, 22, 339-343.

SPENCE, K. W. Cognitive and drive factors in the extinction of the conditioned eye blink in human subjects. Psychological Review, 1966, 73, 445-458.

SPEILBERGER, C. D., \& DeNIKE, L. D. Descriptive behaviorism versus cognitive theory in verbal operant conditioning. Psychological Review, 1966, 73, 306-326. 